ARCHIVO ESPAÑOL DE ARTE, LXXXV, 340

OCTUBRE-DICIEMBRE 2012, pp. 329-349

ISSN: 0004-0428

\title{
ENTRE LA CIENCIA Y EL ARTE. CEROPLÁSTICA ANATÓMICA PARA EL REAL COLEGIO DE CIRUGÍA DE SAN CARLOS (1786-1805)*
}

\author{
Alicia Sánchez Ortiz**, Nerea del Moral y Sandra Micó
}

\begin{abstract}
Se relacionan algunos documentos, muchos de los cuales son inéditos, con la intención de ilustrar algunas dinámicas concernientes a la producción ceroplástica que se llevó a cabo durante el período de 1786 a 1805 en el Real Colegio de Cirugía de San Carlos, de Madrid, cuyos contenidos permiten comprender mejor tanto la gestión como la actividad del citado gabinete anatómico. Asimismo, se exponen y analizan los datos relativos a los cirujanos, maestros cero-escultores y ayudantes que participaron en la creación de la colección.
\end{abstract}

Palabras clave: Cera; Anatomía; siglo XVIII; Artífices; Gabinete; San Carlos.

\section{BETWEEN SCIENCE AND ART: ANATOMICAL WAX SCULPTURE FOR THE ROYAL COLLEGE OF SURGERY OF SAINT CHARLES (1786-1805)}

Several documents, some of them never before published, are here examined in order to illustrate the dynamics surrounding the production of wax sculpture at the Royal College of Surgery of Saint Carlos in Madrid, during the period 1786 to 1805 . Their contents allow for the better understanding of the procedures as well as the activities of this anatomical cabinet. Also studied are the data relating to those surgeons, master sculptors in wax and their assistants who participated in the creation of this collection.

Key words: Wax; Anatomy; $18^{\text {th }}$ century; Artisans; Cabinet; Saint Charles.

\section{Introducción}

A lo largo de la historia, las disciplinas de las artes visuales y la medicina han establecido constantes lazos de intercambio entre ambos saberes. Si por un lado, el trabajo naturalista del artista encontraba apoyo en los avances científicos realizados por los anatomistas y cirujanos, por

* El presente trabajo forma parte de los resultados obtenidos por el grupo de investigación dentro del proyecto $E l$ Arte de la Ceroplástica Anatómica: Caracterización de materiales y metodología de actuación en conservación de colecciones de modelos anatómicos en cera, dentro del Plan Nacional de Proyectos I+D (referencia HAR2009-10679).

** Universidad Complutense de Madrid. 
otro, estos últimos han podido registrar y transmitir sus descubrimientos y conocimientos a través de las diferentes representaciones artísticas de aquéllos. Las figuras anatómicas en cera son máximos exponentes de cómo la estética influyó en el proceso científico y también del modo cómo la ciencia se vio rebasada por el arte. El objetivo era lograr la confección artificial del cuerpo humano con modelos que fuesen capaces de mostrar al erudito la maravillosa construcción anatómica y a la vez que respondiesen al ideal de belleza y perfección perseguido por el artista según los cánones que dominaban en la época que se elaboraron.

El presente artículo saca a la luz datos inéditos sobre la creación de una colección de interés científico-artístico que forma parte de la Historia del Arte de la Ceroplástica a nivel europeo. Si bien este tipo de manifestaciones ha sido objeto de amplios estudios en el ámbito italiano, no ha ocurrido lo mismo en España donde el arte de la cera ha pasado prácticamente desapercibido a pesar de la extraordinaria riqueza y variedad de las piezas conservadas. Entre los trabajos publicados sobre este tema cabe destacar las aportaciones realizadas por Margarita Estella ${ }^{1}$ en el empleo de la cera para la creación de escaparates con escenas populares que se hallan tanto en las clausuras de conventos, las colecciones reales como en casas particulares, además de sus estudios sobre la fabricación de pequeños medallones. Son también dignas de citar las investigaciones efectuadas en este campo por los historiadores del arte Jesús Urrea ${ }^{2}$, Alvar González ${ }^{3}$ y más recientemente por Jesusa Vega 4 .

Entre los motivos que pudieron contribuir al desprestigio académico de la escultura en cera se hayan la repulsión que provoca la visión de este tipo de obras tremendamente verosímiles y el carácter popular de los museos que cuentan con ellas entre sus colecciones, todo lo cual ha favorecido el silencio a su alrededor y el mantenimiento en un segundo plano como simples objetos decorativos o curiosidades que, sin embargo, despertaron en épocas pasadas un elevado interés y fueron altamente valoradas como piezas de los gabinetes.

Las siguientes páginas pretenden poner en valor los modelos escultóricos anatomizados en cera que se han conservado en el Museo de Anatomía "Javier Puerta" de la Universidad Complutense de Madrid. Para ello se han analizado los documentos de archivo de la época en la que fueron creadas estas magníficas obras de arte del siglo XVIII, prestando una especial atención a dos aspectos considerados de esencial relevancia: el ámbito histórico-médico y su problemática en la España de la época, y la relación existente entre los médicos cirujanos y los artífices de las piezas con el fin de comprender mejor el modus operandi de ambos a través del tipo de materiales y de los procedimientos técnicos empleados. Sin duda alguna el conjunto de esta colección, hasta ahora prácticamente desconocido, tiene una gran relevancia en el campo de la historia en tanto en cuanto en sus piezas se funden las disciplinas de la Medicina y el Arte, por lo que este artículo aspira a ser una primera contribución en el contexto español de la ceroplástica anatómica.

\section{El Real Colegio de Cirugía de San Carlos de Madrid}

A petición del catedrático Pedro Custodio Gutiérrez y del Rector Martínez de Bustos y con objeto de formar cirujanos para cubrir las necesidades de la población civil, el Consejo de Castilla ${ }^{5}$ aprobó y aceptó, el 29 de agosto de 1774, la creación en el Hospital General de Madrid de

\footnotetext{
1 Estella, 1993: 149-160; 2009: 75-84.

2 URREA, 1979:485-495.

3 GONZÁlEZ, 1993:41-66.

4 VEGA, 2010b: 434-450

${ }^{5}$ Como Consejo Real, el Consejo de Castilla era la segunda dignidad del Reino, tras el Rey. Fue creado a finales del siglo XIV (1385) por Juan I. En un principio contaba con doce miembros, cuatro de cada uno de los siguientes estamentos: representantes del clero, de las ciudades y de la nobleza.
} 
un nuevo Colegio de Cirugía, conocido bajo el nombre de Real Colegio de Cirugía de San Carlos. Ya en tiempos de Fernando VI habían comenzado los estudios específicos en este saber que se impartían en el Colegio de Cádiz con el fin de dotar de médicos a la Armada; la insuficiencia de cirujanos en el Ejército llevó, algunos años más tarde a que Carlos III autorizase en Barcelona el establecimiento de otro Colegio de Cirugía. Dichas instituciones posibilitaron ejercer en la práctica una enseñanza basada en el cómo y no ya tanto en $e l$ por qué, a la vez que respondían a la demanda creciente de una profunda formación en las ciencias naturales y un adecuado equilibrio entre las disertaciones teóricas y las experiencias prácticas. En palabras de Burke "Se pensaba que la mejor solución era eliminar toda la educación quirúrgica de la universidad y establecer escuelas especiales de cirugía independientes tanto de las universidades como del Protomedicato [...] con el mismo estatus que la universidad. $[\ldots]^{6}$.

Desde un primer momento, la intención de dotar al Colegio de autonomía contó con la oposición del Protomedicato ${ }^{7}$ y de la cofradía de San Cosme y San Damián que veían peligrar su situación privilegiada hasta entonces. De igual modo, mostró su disconformidad la Facultad de Medicina de Alcalá de Henares dado que en ella se enseñaba la medicina de manera clásica ${ }^{8}$.

A pesar de ello, el monarca mantuvo su decisión inicial y en 1774, Carlos III envió a los profesores Antonio Gimbernat ${ }^{9}$ (fig. 1) y Mariano Rivas ${ }^{10}$ a estudiar los últimos métodos de enseñanza de la cirugía en el extranjero. Ambos recorrieron Francia, Inglaterra, Escocia y Holan-

${ }^{6}$ BURKe, 1977: 56.

${ }^{7}$ La medicina española estuvo hasta mediados del siglo XVIII gobernada por el Protomedicato Real. Éste fue fundado alrededor del siglo XV, y entre sus funciones estaban la de otorgar permisos a todos los médicos, arbitrar sus disputas, así como castigar la curandería y la mala praxis. Con ello velaba para garantizar el cumplimiento de los estándares de la práctica médica en España. Sin duda alguna, su principal actividad fue la de definir los requisitos y privilegios, por separado, de médicos, cirujanos, barberos y farmacéuticos. El Protomedicato mantuvo su poder hasta 1779.

${ }^{8}$ En principio el término de medicina clásica se refiere a la medicina que se ejercía en los tiempos clásicos, fundamentalmente en la época griega y greco-romana, aunque hay tratadistas que lo extienden a la medicina árabe y a la Edad Media. Asimismo, son muchas las ocasiones en las que dicho término se emplea inadecuadamente para referirse a antiguo o clásico en relación al trabajo de autores consagrados del pasado.

9 Antonio Gimbernat (1734-1816) se formó como cirujano en el Colegio de Cádiz, bajo la dirección de Pedro Virgili.

${ }^{10}$ Profesor de Cádiz y cirujano de la Real Armada.

Arch. esp. arte, LXXXv, 340, octUBRE-DiCIEMBRE 2012, 329-349, ISSN: 0004-0428 
da, en un viaje que duró cuatro años ${ }^{11}$. En París visitaron el hospital general -nombrado Hotel Dieu-, y presenciaron las lecciones de Macquer, uno de los químicos más adelantados del momento. En Londres fueron a las instalaciones de los hospitales de Santo Tomás, Guy, San Bartolomé y San Jorge, donde conocieron el modo de trabajar de algunos de los cirujanos más eminentes del momento, tales como Smith, Els, Lucas, Pott, Crane, Sharp, Young, Saunders y Hunter $^{12}$, asistiendo a las prestigiosas conferencias de éste último durante 1777. Asimismo visitaron la clínica de Leiden donde había enseñado Hermann Boerhaave. Gimbernat y Rivas no eran en absoluto los primeros cirujanos en estudiar fuera de España, pero sus conocimientos renovados sirvieron para mejorar este campo de estudio ya que de sus viajes "traerían observaciones sobre estudios, operaciones, métodos y regulaciones [de cirugía] en aquellas naciones, escuelas y hospitales donde la formación y la administración fueran mucho mejor"'13.

En la Real Resolución de 21 de Marzo de 1778, el rey pide se disponga un Reglamento que facilite a los cirujanos la asistencia a los enfermos y para ello establece un curso formal de enseñanza de la cirugía en Madrid que se impartiría en el Real Colegio de San Carlos. Encomendará la tarea de construir este centro y establecer su Reglamento, a los Sres. Gimbernat y Ribas en forma de Real Orden de S.M. de 13 de julio de 1779, un precepto constituido por los Reales Hospitales para la enseñanza de la Cirugía en Madrid, dado por los cirujanos de Cámara, Perchet y Virgili ${ }^{14}$, en el que comunica su Majestad al Consejo, las siguientes Resoluciones Reales en Real Orden de 26 de mayo del mismo año ${ }^{15}$, firmada por su secretario y escribano de cámara, Don Antonio Martínez Salazar; de ella cabe destacar lo siguiente: "Que se establezca en Madrid un Colegio y Escuela de Cirugía, conforme en todo al que hay establecido en Barcelona, en quanto á Maestros, Estudios, gobierno interior, honores y exempciones de sus Colegiales, para poder ser empleados en el Exercito y Armada [...]

En abril de 1780 Gimbernat y Ribas comenzaron a trabajar sobre el plan de formación del Colegio y el 14 de julio del mismo año se presentó a la Corona una síntesis del mismo ${ }^{16}$. En la Real Cédula de 1780 (fig. 2), ratificada en 1783, el citado monarca manifestó: "Que habiendo entendido desde mi ingreso al trono el decadente estado de la cirugía en estos mis Reinos, ..., tuve a bien mandar erigir una Escuela Real de Cirugía en la ciudad de Barcelona, ... , para que de este modo se formasen al mismo tiempo cirujanos hábiles para la dotación de los Regimien-

${ }^{11}$ Los resultados de estos viajes son relatados en el Oficio redactado por el Excmo. Sr. D. Miguel de Muzquiz, el 19 de marzo de 1779, y enviado al Excmo. Sr. Conde de Ricla, en el que se indica: "El Rey ha sabido con mucho gusto los progresos y adelantamientos que han logrado estos facultativos (los Sres. Gimbernat, y Rivas): y deseando su Real ánimo que sus luces y observaciones se empleen en beneficio y alivio de sus vasallos, les ha mandado venir á Madrid, en donde se hallan, y quiere S. M. que subsistan asistiendo en el hospital general, hasta que se establezca en esta Corte el Colegio de Cirugía que S. M. tiene premeditado y resuelto.” Gimbernat, 1828: 33-34 y SALCEDO, 1927: 201.

12 JOHN HunTER (1728-1793) fue un extraordinario cirujano inglés. En palabras de Usandizaga ejerció un indudable influjo en el "espíritu creador de San Carlos" (UsandizAGA, 1948: 11) Hay datos de la existencia de una fabulosa Colección Anatómica de Hunter que fue destruida, al parecer, por una bomba, en los ataques aéreos de Londres de 1941. Hunter enfatizaba la necesidad de una sólida formación en anatomía para el cirujano.

${ }^{13}$ Las instrucciones se resumen en AHN, Consejos, Leg. 1368e (Libro de Gobierno), fol. 254-260, Real Cédula, 13 de abril de 1780 .

14 Pedro Virgili (1699-1776) fue un cirujano-barbero de Tarragona. Su enorme interés hacia la anatomía le llevó a viajar, en 1716, a Montpellier para ampliar sus conocimientos en esta materia de modo que pudieran aplicarse en nuevas enseñanzas didácticas en España. Dirigió el primer Colegio de Cirugía en Cádiz.

${ }^{15}$ Real Cédula de S.M. y señores del Consejo por la qual se manda establecer en Madrid un Colegio y Escuela de Cirugía... En Madrid: en la imprenta de D. Pedro Marín, 1780. En Hospital Universitario de San Carlos. Eudema, 1787-1987 (Con motivo del bicentenario de la Fundación del Hospital Universitario de San Carlos se publica esta edición Facsímil de la Real Cédula Fundacional de Carlos III y la Disertación Inaugural de Antonio Gimbernat.)

16 SALCEDO, 1927. Tomo segundo: 146-148. 
tos ,..., como el establecido en Cádiz con reglamento provisional ... expedido en el interior Reynado, con el objeto de que la Marina estuviese surtida de cirujanos hábiles". Posteriormente y "con el propio objeto de la utilidad pública..." pide a la Junta de Consiliarios de los Reales Hospitales que dispusiesen un Reglamento y éstos le contestan manifestando" la precisión de erigir en los Reales Hospitales un Colegio de Cirugía". Una vez comunicado a su Consejo y tras el informe de éste y del Duque de Losada en calidad de Sumiller de Corps, decide: "... He venido en resolver se establezca en Madrid un Colegio, y Escuela de Cirugía, conforme en todo al que hay establecido en Barcelona, ... En dicho Colegio se han de admitir para su enseñanza indistintamente a cuantos quieran venir a aprender esta facultad, ya sean naturales de Madrid, o de cualquier otra parte de España, ...” Y añade “... últimamente declaro, que el referido Colegio de Cirugía se ha de gobernar, y manejar con absoluta independencia del Tribunal del Protomedicato, del de Cirugía y de la Junta de Hospitales, y que solamente ha de depender de la protección de el mi Consejo en los términos expresados, excepto solo a los exámenes de sus alumnos que como queda dicho se han de hacer en el Tribunal del Protocirujanato".

El Real Colegio de Cirugía estuvo inicialmente ubicado en el sótano del Hospital General y más tarde se trasladó a la planta baja del pabellón lateral que estaba aún en construcción, tal y como consta en la Real Cédula de 1780: "Que dicho Colegio se ha de situar en la nueva Fábrica del Hospital General en las piezas que el mi Consejo tenga por conveniente destinar, debiendo ser de cuentas de dicha Fábrica los gastos de su preparación y acomodo". Y añade que se estableciese: “... baxo la inmediata proteccion del mi Consejo, y con independencia de la Junta de Hospitales y Protomedicato... al lado del Hospital General el edificio en que ha de darse la

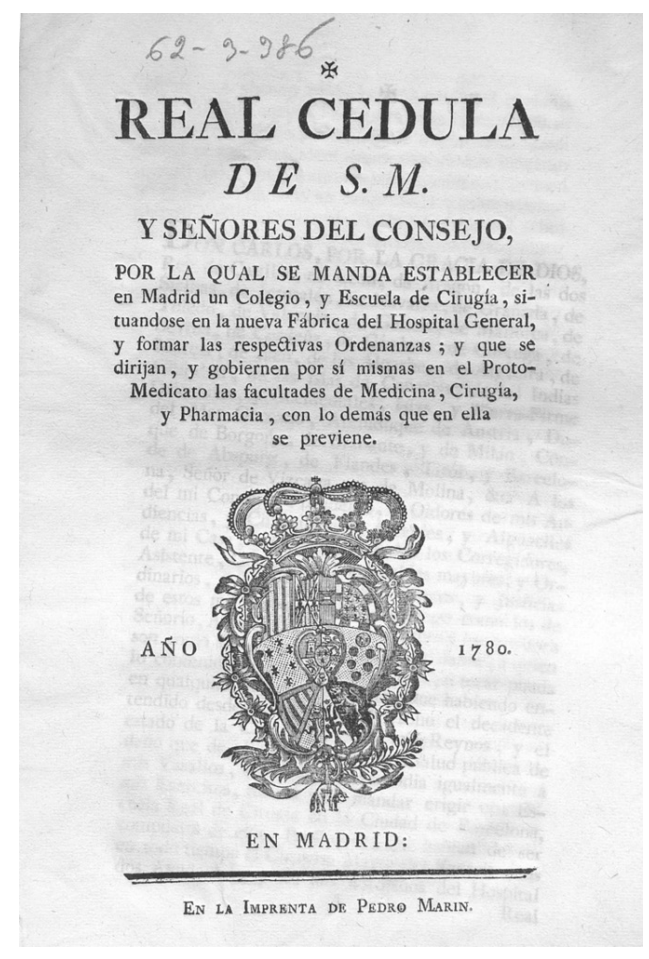

Fig. 2. Portada de la Real Cédula de establecimiento del Colegio de Cirugía de San Carlos, de 1780. Biblioteca Histórica Universidad Complutense de Madrid.

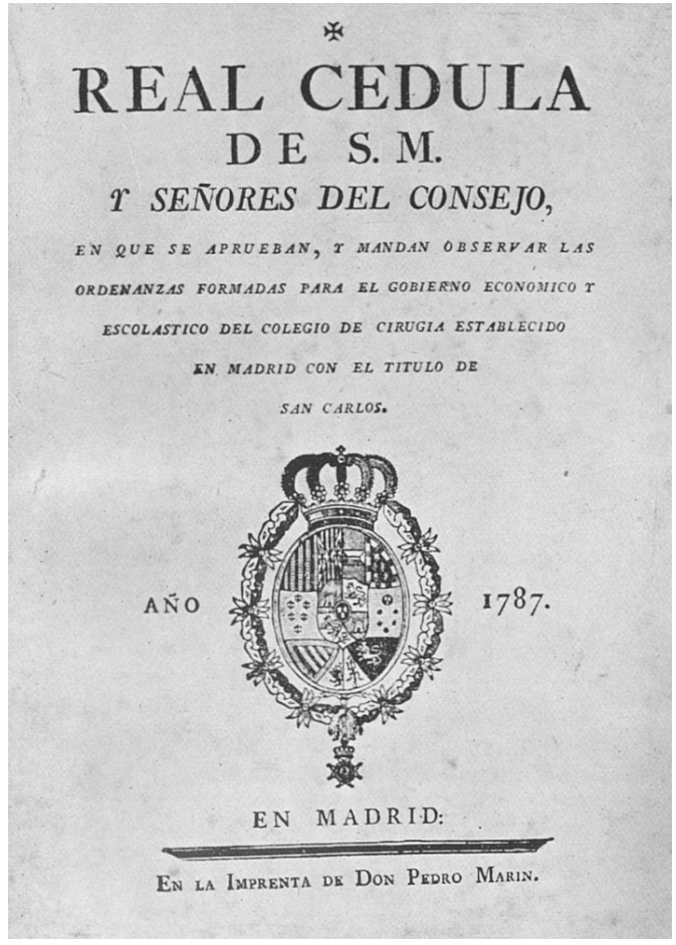

Fig. 3. Portada de las Ordenanzas del Real Colegio de Cirugía de San Carlos, del año 1787. Biblioteca Histórica Universidad Complutense de Madrid. 
enseñanza pública; cuyo plan ha formado...don Francisco Sabatini..." Gimbernat y Ribas se mostraron reacios a esta decisión pues consideraban que era mejor situarlo en el Hospital de la Pasión.

Por Real Cédula del 24 de febrero de 1787 (fig. 3) se aprueban las Ordenanzas de dicho Colegio de Cirugía y se establece la independencia del mismo de los Reales Hospitales, debiendo correr a cargo de estos últimos la dotación de los alimentos, medicinas, cama, ropas y enfermeros. Además debían proveer de cadáveres al Colegio para las disecciones, preparaciones y experimentos. Finalmente, su inauguración tuvo lugar el 1 de octubre 1787 con asistencia de los ministros del Consejo de Castilla, y del duque de Híjar, que era además Hermano Mayor de la Junta de los Reales Hospitales.

El 12 de marzo de 1799, el rey ordenó que el Real Colegio de Medicina, que estaba situado en la parte más alta del Hospital General, se uniera al Real Colegio de Cirugía de San Carlos, formando ambas instituciones un único establecimiento con la creación de un solo Cuerpo de catedráticos. De esa manera se conseguía fundir los estudios de médicos y cirujanos que pasaron a depender de una Junta General Común ${ }^{17}$. Pero las luchas constantes entre unos y otros provocaron la separación provisional de ambas docencias hasta que, en 1821, las $\operatorname{Cortes}^{18}$ decidieron unificar dichos saberes en San Carlos. Es a partir de entonces cuando el Real Colegio de San Carlos tomó el nombre de Escuela Especial de la Ciencia de Curar.

En 1827 se creó el Real Colegio de Medicina y Cirugía de San Carlos ${ }^{19}$ por influencia de Pedro Castelló y Ginestá ${ }^{20}$; años más tarde, al unificarse los Colegios y las Universidades, aquél pasó a denominarse Facultad de Ciencias Médicas de la Universidad de Madrid. Una vez acabada la contienda de la Guerra Civil española se abrió un largo proceso de restructuración de las enseñanzas. Fue en esa etapa cuando se configuraron las nuevas colecciones requeridas para el trabajo docente y de investigación universitaria. El actual Museo de Anatomía y Embriología "Javier Puerta" de la Facultad de Medicina de la Universidad Complutense de Madrid es así heredero del Gabinete Anatómico creado en el Colegio de San Carlos de Madrid a finales del siglo XVIII.

\section{La creación del Gabinete Anatómico}

Las primeras noticias que se tienen de la adquisición de material e instrumental quirúrgico para el Gabinete Anatómico se remontan a 1752 y se concretan en el encargo efectuado por el monarca Carlos III, mediante Real Orden de 13 de noviembre, al entonces cirujano de la Corte española, José Fernández ${ }^{21}$,que se encontraba pensionado en París. El pedido ascendió a una suma total de 29.868 libras y fue llegando en partidas diversas a tenor de los datos encontrados

${ }^{17}$ El 14 de marzo de 1818, la Junta Superior Gubernativa precisa las funciones de los cirujanos.

18 Disposiciones de las Cortes en 1821 sobre la unión entre médicos y cirujanos.

19 Real Decreto de 16 de junio de 1827 disponiendo que los Reales Colegios de Cirugía-Médica se denominen de Medicina y Cirugía y que en ellos se enseñe la Medicina en todas sus partes, sin que por esto se altere la enseñanza de la Medicina en las Universidades.

${ }^{20}$ Cirujano castrense y catedrático de los Colegios de Cirugía de Santiago de Compostela, Barcelona y San Carlos de Madrid, fue nombrado Marqués de la Salud por su acierto en curar a Fernando VII. Se le considera el verdadero artífice de la unión.

${ }^{21}$ José Fernández "[...] fue cirujano del Hospital General de la Corte de Madrid durante los años centrales del siglo XVIII; fundador del 'Colegio de Cirugía' de Madrid, que funcionó, vinculado a los Hospitales, con anterioridad a la creación del Colegio de San Carlos, en aquel primitivo 'colegio', [...], se llevó a cabo una labor docente y científica preferentemente anatomoquirúrgica, y tuvo en José Fernández uno de sus más representativos cirujanos. De este profesional sabemos que fue pensionado por Real Orden de 10 de octubre de 1751, con la misión de "instruirse y 
donde se hace referencia a una primera caja con instrumental para la talla, una cuarta con elementos de obstetricia, una sexta con instrumentos relativos a la anatomía y, a destacar, una décima con "figuras de cera para la enseñanza anatómica"22. El conjunto de este material quedó bajo su custodia, por cuya responsabilidad percibiría diariamente seis reales de vellón ${ }^{23}$.

Fue a partir de la Real Cédula de S. M. de 1787 cuando quedaron establecidas las normas para el Gabinete Anatómico ${ }^{24}$. Con el fin de ayudar a mejorar el estudio de la Cirugía, el monarca ordenó la creación de un colección de piezas anatómicas, elaboradas con diversos materiales ${ }^{25}$. Asimismo, estableció la necesidad de llevar a cabo los denominados Informes del Cirujano, en los que se anotarían todos los datos fundamentales de cada pieza siendo custodiados conjuntamente para servir en las lecciones públicas de anatomía. El Gabinete anatómico estaría al cuidado del Maestro de Anatomía sobre quien recaería la obligación de inventariar sus piezas y procurar la sustitución de aquéllas que se hubiesen deteriorado o extraviado, quedando a cargo del Colegio los gastos derivados de estas tareas ${ }^{26}$.

Con la finalidad de favorecer el estudio del cuerpo humano mediante preparaciones, disecciones y experimentos, se admitió el manejo de cadáveres procedentes del Hospital General. En este sentido ya Gimbernat y Ribas, en 1780, habían solicitado al monarca que se previese un lugar de comunicación entre dicho edificio y las instalaciones del Colegio, con el fin de evitar que el trasiego de los cuerpos por la calle pudiese provocar rechazo entre la gente.

\section{Los artífices de los modelos artificiales en cera}

Siempre en sintonía con el pensamiento y los gustos dominantes de cada período histórico, los métodos y los instrumentos de enseñanza médica han ido cambiando con el transcurrir del tiempo. Durante la segunda mitad del siglo XVIII, la comunión de las actividades científicas y artísticas dio como fruto la ceroplástica anatómica. Las piezas artificiales en cera supusieron un gran avance con respecto a la disección e ilustración anatómica tradicional de los siglos precedentes $^{27}$. Estos modelos tridimensionales ${ }^{28}$ permitían realizar reproducciones muy precisas en las que los estudiantes disponían de una imagen concreta y práctica, y despertaron fascinación ante la exactitud con que se lograba reproducir el detalle anatómico. Cada escultura era el re-

\footnotetext{
perfeccionarse más en la Cirugía", ' Desde 1774 y hasta su muerte fue Primer Cirujano de Cámara de Carlos III. (RIERA, 1982: 61-62)

22 RIERA, 1982: 58

23 RIERA, 1982: 62.

24 En Madrid Imprenta de Pedro Marín.

25 Parte cuarta. Oficinas, Oficiales y Sirvientes del Colegio, Sección I. Oficinas. Capítulo II: "Para que el estudio de la Cirugía se puede hacer en esta escu[e]la con la mayor perfeccion en la parte anatómica, que es la principal de esta Facultad: ordeno que se forme una colección de piezas anatómicas, así naturales como artificiales, de cera ú otras materias, con buen órden en una sala capaz y dedicada expresamente á este fin, recogiendo en ella los preparados frescos y secos, y el mayor número posible de partes moles, y duras del cuerpo humano, conservadas las que lo necesiten en vasos y licores [...] Todos los Maestros del Colegio deben contribuir á la formacion de este gabinete an[a]tómico [...].

${ }^{26}$ Usandizaga, 1948:60.

${ }^{27}$ La evolución de los tratados de anatomía en lo referente a las ilustraciones ha estado sujeta a los avances y perfeccionamientos técnicos realizados en el campo del grabado, desde la inicial entalladura en hueco a los procedimientos propios de la talla dulce a buril o las impresiones a color. Estos progresos permitieron a los artistas realizar extraordinarias láminas en las que ha quedado perpetuado, de manera gráfica, el trabajo de los anatomistas. Para un análisis de la influencia que ejerció el arte del grabado y sus diferentes procesos técnicos en la ilustración médica remitimos a PARK, 2006.

28 Otros métodos tridimensionales, como la momificación o el embalsamamiento, no eran resistentes a la usura del tiempo y terminaban por arruinar el laborioso trabajo del artesano. Por ello se concretizó elaborar un cuerpo anatómico artificial en cera.
} 
sultado de un elevado perfeccionamiento artístico en el que se plasmaba una estética muy especial a través de la cual se mostraba al público cuerpos en cera, que parecían vivos, en los que el espectador podía realizar un viaje sistemático comenzando por la anatomía de la superficie para ir ahondando en las diversas cavidades corporales de sus órganos, vasos sanguíneos y nervios.

Los artistas competían para realizar sus trabajos lo más exactos posible, desarrollándose una interesante producción de preparaciones a lo largo de la segunda mitad del siglo XVIII y la primera mitad del siglo XIX. Fue en el Real Gabinetto di Fisica e di Storia Naturale ${ }^{29}$, de Florencia -hoy conocido como La Specola-, donde se popularizó la producción de ceras anatómicas gracias a los trabajos de las parejas de anatomistas y modeladores formadas por Felice Fontana y Giuseppe Ferrini, por un lado, y Antonio Mateucci, Paolo Mascagni y Clemente Sussini, por otro, influyendo en otros escultores y escuelas contemporáneas italianas y extranjeras.

Desde su nombramiento, uno de los principales objetivos de Gimbernat fue el desarrollo y crecimiento del Gabinete Anatómico y Patológico del Real Colegio de Cirugía de San Carlos. Impresionado gratamente por la colección del cirujano inglés, John Hunter ${ }^{30}$, quien había atesorado cerca de mil trescientas piezas de ceras anatómicas, señaló el interés en adquirir alguna de las mismas para Madrid $^{31}$. Si a ello añadimos que durante su estancia de pensionado en París dirigió, junto a Rivas, la elaboración de doce piezas de anatomía en cera, cuyo disector fue Ignacio Lacaba ${ }^{32}$, destinadas al citado gabinete, se puede deducir su interés en desarrollar una colección similar en España. Probablemente no todas las esculturas que componen la colección del antiguo Colegio hayan sido elaboradas en las dependencias del mismo. En el Libro de cuentas del Real Colegio de San Carlos se recogen algunos pagos referidos al costo de "piezas anatómicas en cera" 33 , no pudiendo concretar si los mismos se destinaron a costear la adquisición de materiales para la elaboración de las figuras en las dependencias del Colegio o a la compra de modelos pertenecientes a otros talleres de fuera de España.

Los documentos de archivo indican que entre los primeros modelos en cera para el Gabinete se encontraron las presentaciones fetales de los nueve meses de gestación. Por orden del rey se solicita, en 1787, un informe sobre los progresos del Colegio y su actual estado obteniendo como respuesta: "La formación del Gabinete Anatómico y Patológico (...) se halla muy adelantado, asi en piezas naturales simples y preparadas, como en artificiales de cera. De estas últimas se cuentan hoy 57, trabajadas todas superiorm(en)te (...) Entre ellas merece atencion especial la colección de las q(u) e representan los diversos estados de la preñez desde la concepcion hasta el parto, las varias posiciones del feto dentro de la matriz, y su comunicacion con la madre: circunstancias todas esencialísimas pa(ra) el acierto en la práctica de los Partos, y q(u)e en esta colección se presentan de bulto y al natural (...) Para complem(en)to de esta materia se están concluyendo en cera varias piezas q(u)e manifiestan progresos del Parto natural, y todas las especies de los trabajosos y preternaturales, de manera q(u)e esta colección puede actualm(en) te tener lugar entre las celebradas de Europa" ${ }^{34}$. Usandizaga recoge en su Historia de la Obstetricia en España, de 1944, a modo de listado, algunas de estas preparaciones: "Grávida a

${ }^{29}$ Este famoso gabinete fue dirigido en sus orígenes por el abad Felice Fontana e inaugurado en 1775.

30 JoHn HunTER (1728-1793) trabajó con su hermano anatomista, William. En 1783 se mudó a Leicester Square, en Londres, donde abrió su colección de preparaciones y rarezas al público en forma de Museo (BuzZI, 1996: 209-224). Sus contribuciones anatómicas alcanzaron gran reconocimiento.

31 SALCEDO, 1927: tomo I, 237.

32 Vega, 2010a: 455.

33 Libro de cuentas: entradas y salidas del caudal de dotación señalado al R(ea)l Colegio de San Carlos, establecido en Madrid: año de 1787(-1815). BH MSS 926.

${ }^{34}$ Libro de representac(iones), respuestas y orden(anzas) de los años anteriores y R(eale)s Ordenes con arreglo a la ordenanza de (cirugía). Madrid, 1787-1817. (BH MSS 927) (Manuscrito). 
término, Embarazo de tres meses, Embarazo de cinco meses, Útero grávido a término, Embarazo gemelar, Cabeza por encima del estrecho superior, Cabeza encajada sin rotar, Cabeza encajada en posición occípito-pubiana, Cabeza encajada en posición occípito-sacra, Cabeza encajada en probable presentación bregmática y Presentación de nalgas" 35.

Las ceras obstétricas constituyen uno de los capítulos más significativos de la ceroplástica y fueron cruciales en el desarrollo de la Medicina. Con ellas se conseguía mostrar la físiología y la patología del aparato genital femenino, las fases del embarazo, así como las diversas presentaciones y situaciones fetales y del parto. Eran consideradas de enorme valor didáctico por la eficiencia demostrativa tridimensional de la gestación, un fenómeno biológico dinámico, difícilmente explorable con las técnicas instrumentales disponibles en la época. El estudiante y el propio médico pasaron de utilizar dibujos bidimensionales contenidos en los tratados de anatomía, a poder tocar y evaluar desde cualquier punto de vista todo aquel conocimiento gracias a los modelos artificiales tridimensionales. Así las explicaciones en el aula acompañadas del modelo apropiado resultaban tanto más claras, desarrollándose la labor de enseñanza de una manera más precisa y plena ${ }^{36}$.

La observación de este tipo de artefactos realizados en cera lleva a cuestionarse las relaciones entre realidad y ficción. En ocasiones el modelado de la pieza se realizaba a partir de las ilustraciones de célebres libros de anatomía; otras, se mostraban conformaciones anatómicas para su observación que raras veces se presentaban en la naturaleza. Es muy probable que muchos de los modelos artificiales en cera del Gabinete fuesen elaborados por los cero-escultores no a partir de disecciones pues “(...) por justos motivos, no se pueden demostrar en los cadáveres las varias situaciones del feto en los diferentes estados de la preñez (...) "37, sino inspirándose en las láminas contenidas en algunos de los tratados de anatomía de la época. En este sentido, es digno de mención la enorme similitud en las posiciones y en los detalles existentes entre las posiciones fetales que aparecen en las diversas láminas grabadas (figs. 4, 6 y 8) por el inglés Charles Grignion $^{38}$, a partir de los dibujos de Jan van Riemsdyck en la mesa de disección del cirujano ${ }^{39}$, contenidas en el famoso libro de William Smellie ${ }^{40}$, A Sett of Anatomical Tables, with Explanations and an Abridgement of the Practice of Midwifery, publicado en 1754, y los modelos artifi-

\footnotetext{
35 UsAndiZaga, 1944: 235.

${ }^{36}$ Durante el siglo XVIII, en Occidente, los nacimientos eran asistidos por parteras (no formadas desde un punto de vista clínico) que se desplazaban a la propia casa de la parturiente. Este tipo de trabajos no recaerá en manos masculinas hasta finales del citado siglo gracias a los increíbles logros y avances que se consiguieron en esta época en el ámbito de la obstetricia. A partir de ese momento el embarazo y el parto dejaron de ser tratados como preocupaciones propias del hogar, pertenecientes al ámbito femenino, para ocupar un puesto relevante entre los estudios de los cirujanos y médicos, quienes comenzaron a asistir a las mujeres durante el parto recibiendo por ello los apelativos de hombresparteras u obstetras. En ello tuvieron gran repercusión los tratados ilustrados de anatomía y los atlas obstétricos, destacando los trabajos publicados por William Smellie y William Hunter, especializados el primero en mostrar normativas aplicables a la gestación y el parto tanto normales como problemáticos, y el segundo, en la morfología gestacional (MASSEY, 2005: 73-74). Aunque en Francia, desde 1550 a 1730, se había generado un amplio estudio sobre la obstetricia que dio como fruto importantes contribuciones, fueron los dos personajes nombrados quienes marcaron el paso hacia el tratamiento científico de la cuestión. La extraordinaria precisión alcanzada en las imágenes de las ilustraciones contenidas en sus tratados pudo contribuir, de manera determinante, al desarrollo de los modelos artificiales en cera. (McTAVISH, 2004: 25-45).

37 Gaceta Oficial del Colegio, del viernes 12 de noviembre, de 1790 (GARCíA DEL REAL, 1934: 750-752).

${ }^{38}$ Charles Grignion (1717-1810) ejerció su actividad en la ciudad de Londres donde alcanzó un gran renombre gracias a su extraordinaria habilidad con el dibujo y la pureza de sus líneas.

39 (MASSEY, 2005: 77).

40 William Smellie (1697-1763) inició la enseñanza de la obstetricia en Londres en la primera mitad del siglo XVIII. Para mostrar a los estudiantes sus conocimientos durante las clases sobre prácticas ginecológicas, encargó la fabricación de maniquíes revestidos de cuero.
} 
ciales en cera de las esculturas realizados por Juan Cháez y Luigi Franceschi para la colección del gabinete madrileño (figs. 4-9). Sin duda alguna las enseñanzas de dicho obstetra gozaban de un enorme prestigio en la época en que se elaboraron las esculturas de bulto redondo ${ }^{41}$.

Para la creación de una escultura en la que se observa un útero grávido se pagó a Lacaba, el 30 de diciembre de 1790, la cantidad de 8267 reales de vellón, tal y como consta en el Libro de cuentas $^{42}$. En la Gaceta Oficial del Colegio se hace referencia a una figura de feto de cuatro meses que aparece descrita como sigue: "[...] En ésta se demuestra el tamaño y situación propia de un feto de cuatro meses y de las demás partes anexas a él, y la estructura anatómica de toda la pelvis y sus relaciones con los lomos y los músculos que mueven el fémur, alguno de los mo-

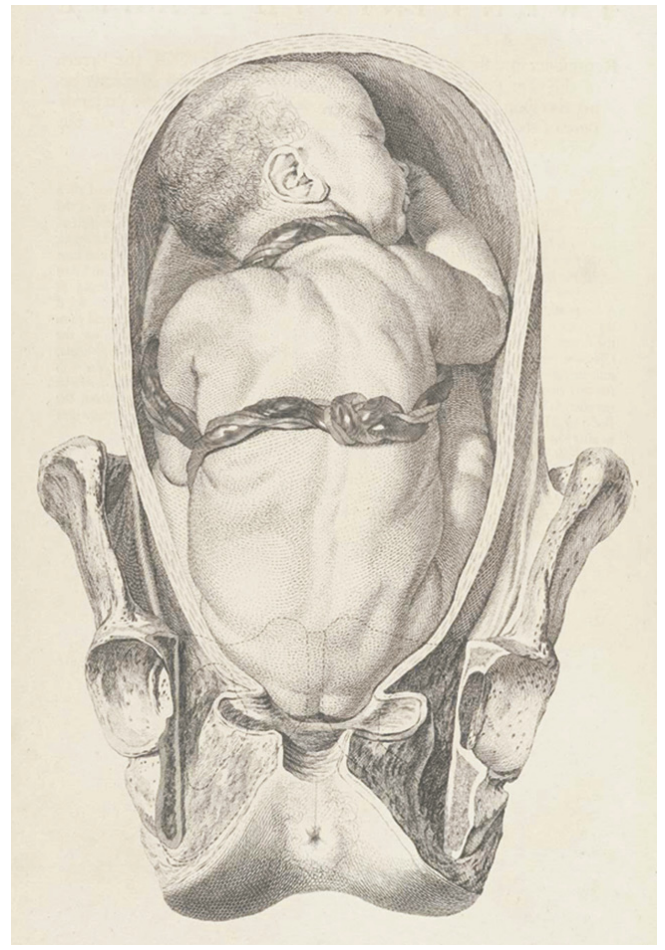

Fig. 4. Lámina XXIX del tratado anatómico de William Smellie, A sett of anatomical tables, with explanations, and an abridgment, of the practice of midwifery, London printed (s.d.), 1754.

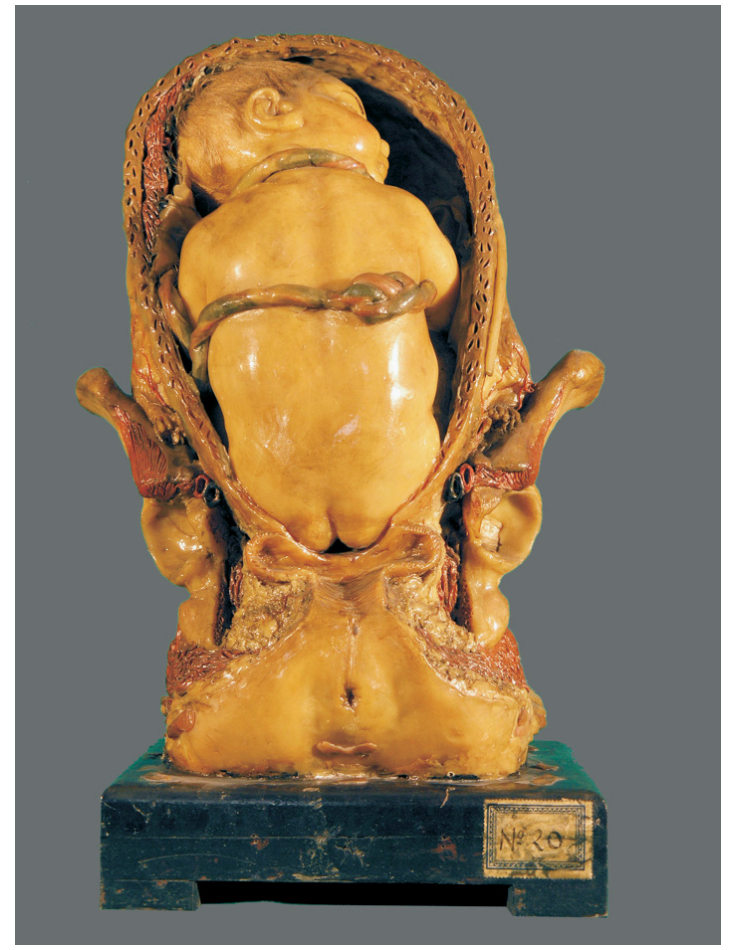

Fig. 5. Juan Cháez y Luigi Franceschi, Modelo anatómico fetal. Escultura de tamaño natural en cera, siglo XVIII. Museo de Anatomía "Javier Puerta", n. ${ }^{\circ}$ inv.: 147. Facultad de Medicina, Universidad Complutense de Madrid. Se observa la disección corte coronal de un útero gestante que contiene un feto en presentación de nalgas con una vuelta de cordón y un nudo en el mismo.

${ }^{41}$ El Atlas de Smellie se focaliza en la zona pélvica de la mujer. Muestra el crecimiento gestacional y las distintas situaciones del parto, incluyendo todas las dificultades posibles en la mesa de disección. Los grabados de sus ilustraciones son de una precisión máxima porque fueron realizados a partir de disecciones de cadáveres de mujeres embarazadas, que en ocasiones, él mismo practicaba. Tanto es así que sirvió de guía fiel a los obstetras del siglo XVIII en la asistencia de partos. (MASSEY, 2005: 76-77, 83).

42 Libro de cuentas: entradas y salidas del caudal de dotación señalado al R(ea)l Colegio de San Carlos, establecido en Madrid: año de 1787 (-1815). BH MSS 926. 


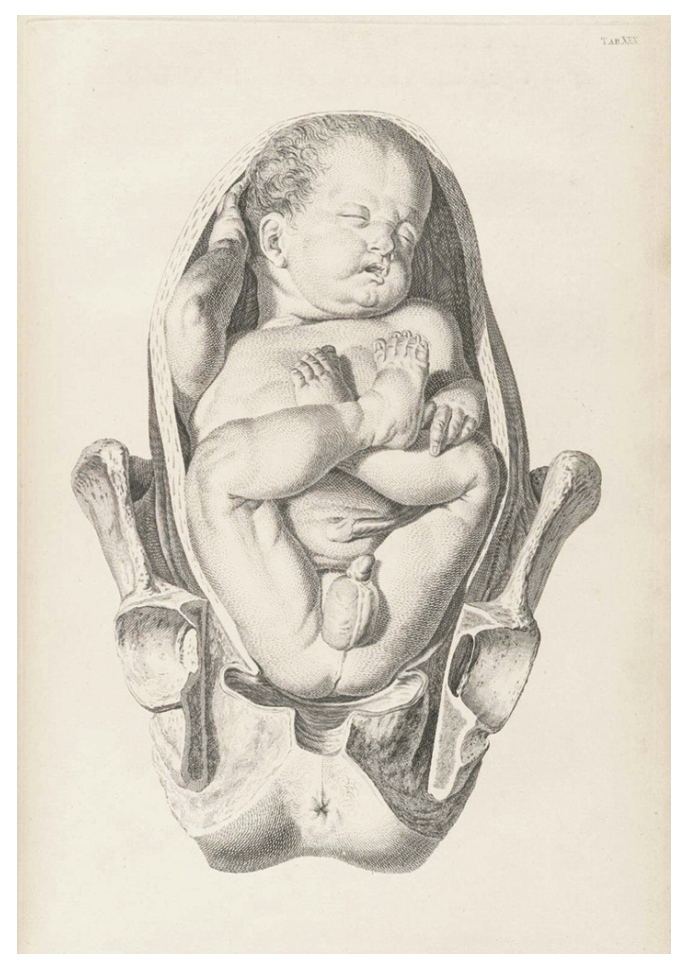

Fig. 6. Lámina XXX del tratado anatómico de William Smellie, A sett of anatomical tables, with explanations, and an abridgment, of the practice of midwifery, London printed (s.d.), 1754.

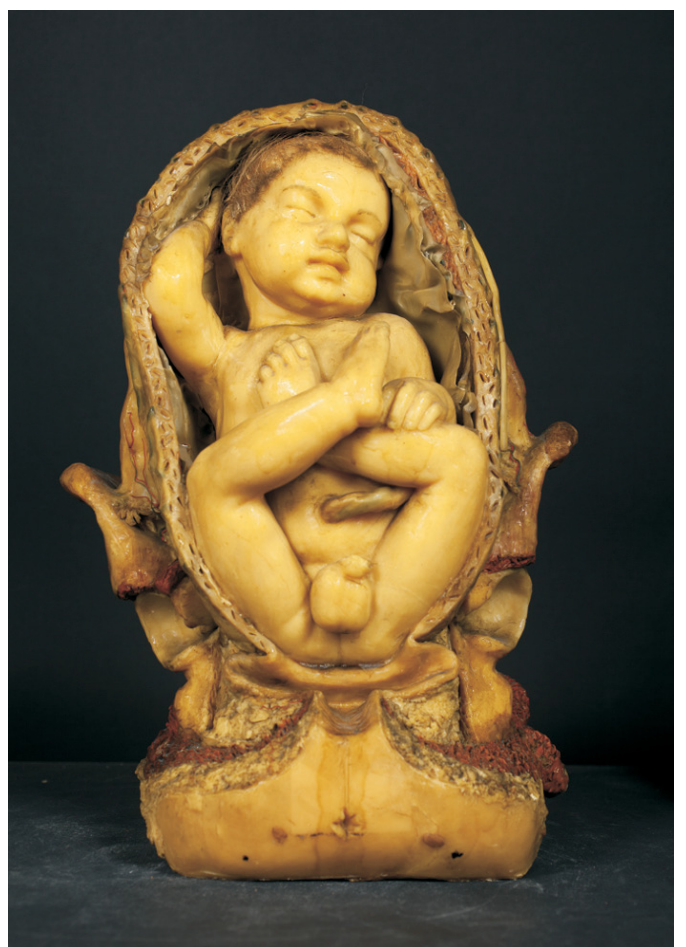

Fig. 7. Juan Cháez y Luigi Franceschi, Modelo anatómico en posición fetal. Escultura de tamaño natural en cera, siglo XVIII. Museo de Anatomía "Javier Puerta", n. ${ }^{\circ}$ inv.: 148. Facultad de Medicina, Universidad Complutense de Madrid. Modelo de útero gestante con dilatación apreciable, en el que se observa un feto varón en presentación de nalgas puras.

tores de la pierna, los nervios lumbares y sus prolongaciones, y las numerosas ramificaciones de arterias y venas se distribuyen desde la última vértebra dorsal hasta la mitad del muslo"43.

En cuanto a la figura femenina de cuerpo entero que muestra un embarazo a término -a la que se refiere Usandizaga como "Mujer a término yacente o Parturienta con el vientre abierto"44_, según el Libro de Cuentas del Colegio, fue realizada por el escultor Juan Cháez y el modelador de cera Luigi Franceschi a partir de las disecciones de Ignacio Lacaba ${ }^{45}$, en un período de tiempo

43 Gaceta Oficial del Colegio del viernes 12 de noviembre de 1790 (GARCíA DEL REAL, 1934: 750-752).

44 UsandiZAGa, 1944: 235.

45 Ignacio Lacaba fue disector en el Real Colegio de Cirugía de San Carlos hasta febrero de 1789 en que su plaza quedó vacante al ser promocionada por S.M. a la Cátedra de Anatomía del Colegio (Libro de representaciones, respuestas y ordenanzas..., 1787-1817), aunque a este respecto hay dudas puesto que según constata Aparicio Simón en su Tesis Doctoral de 1956, Lacaba dejaría libre la plaza en 1795, lo cual, siguiendo los trabajos de Gabinete año por año, 
comprendido entre 1789-1790. Una anotación realizada el 30 de diciembre de 1789 indica que aquél percibió la cantidad de 8.173 reales de vellón por la elaboración de la "Embarazada a término", lo que lleva a pensar que los trabajos se prolongaron. Así lo corrobora el dato encontrado en la Gaceta Oficial del Colegio, del viernes 12 de noviembre de 1790, donde se realiza una minuciosa descripción de esta pieza: "[...] se ha construido una primorosa figura, que representa con toda propiedad una mujer muerta al noveno mes de preñada. En ella se ve, abierto el vientre, la natural posición y volumen del útero grávido, e igualmente la situación del hígado, estómago, omento e intestinos, con los vasos sanguíneos, según ha quedado después de la sección." Aparecen nuevos gastos por la escultura de la Parturienta, con fecha 29 de diciembre

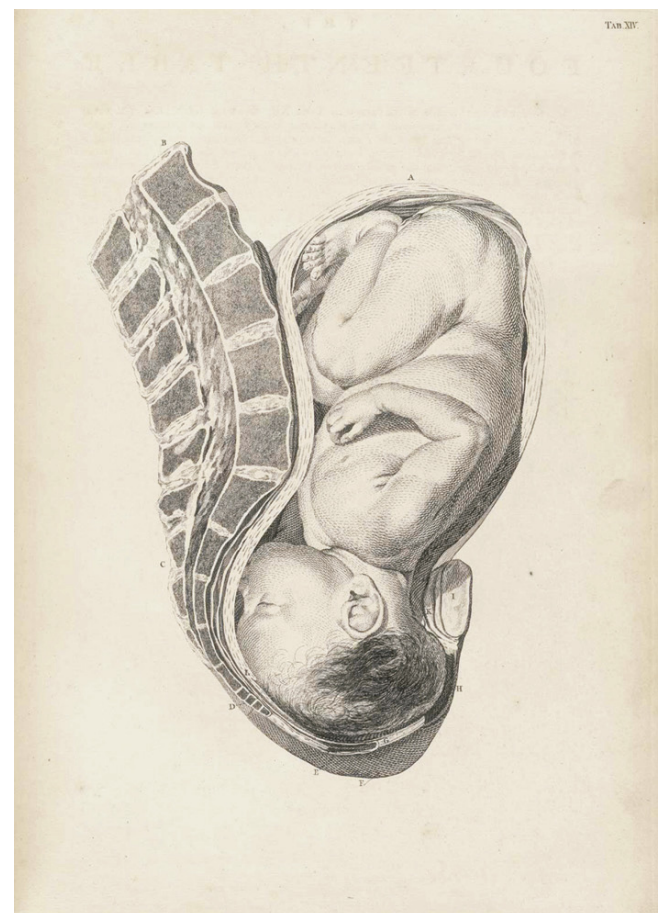

Fig. 8. Lámina XIV del tratado anatómico de William Smellie, A sett of anatomical tables, with explanations, and an abridgment, of the practice of midwifery, London printed (s.d.), 1754.

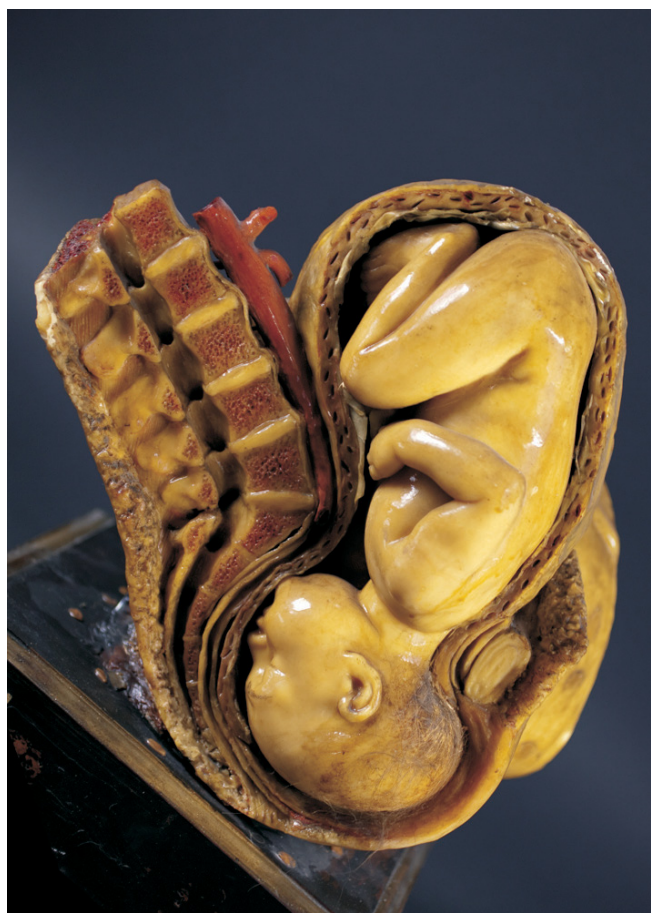

Fig. 9. Juan Cháez y Luigi Franceschi, Modelo anatómico en posición fetal. Escultura de tamaño natural en cera, siglo XVIII. Museo de Anatomía "Javier Puerta", n. ${ }^{\circ}$ inv.: 126. Facultad de Medicina, Universidad Complutense de Madrid. Disección parasagital abdominal donde se evidencia un embarazo a término. Se observa la presentación occipitoiliaca anterior del feto ya encajado en el canal del parto.

nos parece, tiene más sentido. Fue autor en 1796, junto a Jaime Bonélls, de un Tratado en la materia que fue el seguido por muchas Universidades españolas durante largo tiempo, ya que suponía un tremendo avance frente a escritos anteriores. Un año después, en 1797 fue nombrado Cirujano de Cámara. 
de 1790, recibiendo Gimbernat la cantidad de 18.074 reales de vellón; el 30 de diciembre del mismo año, se pagó a Lacaba, por cera y trabajos de disección efectuados para el modelo, 8.949 reales de vellón.

El modelo artificial en cera de "La Parturienta" (fig. 10) del gabinete anatómico de San Carlos tiene una serie de peculiaridades que la hace diferente de las tradicionales venus médicas ${ }^{46}$ existentes en otras colecciones europeas. En primer lugar, la figura no se presenta recostada o tumbada, sino sentada de modo que el escultor respetó con gran realismo la praxis obstétrica del siglo XVII ${ }^{47}$. La postura decúbito supino en la que se encuentra con las caderas semi-flexionadas, sentada en una silla, de forma que el sacro permanece sin apoyo y con posibilidades de moverse, era recomendada en los tratados de la época. Extraordinaria por su rareza, es posible que los cero-escultores se inspirasen en el grabado que aparece en la traducción "Short Introduction to Anatomy" Isagoge del Tratado de Anatomía del útero de Berengario de Capri ${ }^{48}$ (fig. 11). Además, se trata de una escultura en bulto redondo, ejecutada en una única pieza, en la que el abdomen se encuentra diseccionado en cuatro partes revelando en su interior un feto perfectamente formado, a diferencia de las venus anatómicas de la época que solían estar compuestas por partes desmontables que permitían acceder al interior del cuerpo para facilitar la observación anatómica de los diversos órganos ${ }^{49}$. Por otra parte, el artista ha dotado al rostro de la figura de una expresión de dolor y de abandono ante el acontecimiento, -con los ojos cerrados y la boca semiabierta- muy próximos al carácter expresionista de la imaginería barroca española y bastante distante del idealismo italiano cuyas venus emanan sensualidad a través de expresiones relajadas y posturas deleitables cercanas al erotismo.

En lo referente a los artífices que ejecutaron estas ceras obstétricas se sabe que en 1788, Juan Cháez, profesor de escultura, solicitó un puesto en el Colegio de Cirugía " [...] pa[ra] moldar y pintar las piezas Anatómicas en cera [...] bajo las órdenes de Ignacio Lacaba. El 28 de febrero del mismo año consta en el Libro de representaciones el informe redactado por Pedro de Lesera,

\footnotetext{
46 Se desconoce el origen exacto del apelativo "venus" para las figuras anatómicas femeninas de cuerpo entero. Roberta Ballestriero señala que las estatuas anatómicas diseccionadas de mujeres reclinadas comenzaron a denominarse "venus médicas" en referencia directa a la Venus de Médici, haciendo alusión a la proporción y estética del canon de belleza clásico femenino representado por esta escultura del período helenístico. Posteriormente, el término genérico de "venus" se aplicó a cualquier figura de mujer idealizada. Para una información más detallada a este respecto remitimos a BALLESTRIERO, 2009:230-232 y a MORRIS-KAY, 2010:158-176.

47 Durante el siglo XVII, en toda Europa, era tradicional parir en posición sentada en una silla especialmente denominada silla de parto o silla obstétrica. El cambio a la posición horizontal parece producirse a lo largo del siguiente siglo, siendo el primero y uno de los principales defensores el médico partero de la corte francesa Françoise Mauriceau, si bien se considera que el abandono total de la silla obstétrica se produjo en 1778 con el parto en posición horizontal de María Teresa, hija de la reina María Antonieta. Parece lógico pensar que estos datos se refieren, sobre todo, a la gente que podía permitirse estos "lujos", y no al pueblo llano que casi seguro, mantuvo por más tiempo las antiguas costumbres, incluida la posición del parto.

48 A Jacopo Berengario da Capri (1460-1530) se le atribuyen los primeros tratados de anatomía con ilustraciones. El original en latín es Carpi Commentaria cum amplissimis additionibus super Anatomia Mundini una cum texto ejusdem in pristinum \& verum nitorem redacto, publicado en Bolonia por Girolamo de'Benedetti en el año 1521 (PARK, 2006: 271, nota 8 y 333, nota 25). Asimismo, figura como editor del Tratado de Galeno "De anatomicis administrationibus" traducido por Demetrios Chalkokondyles, en 1529 (PARK, 2006: 300, nota 40).

49 Los modelos artificiales, entre los que se pueden incluir las venus anatómicas, no estuvieron destinados sólo a un observador especializado, el médico o el estudiante de medicina, sino que se dirigían a un público más amplio con objeto de popularizar la ciencia bajo un pretexto claramente artístico. Pequeñas figurillas, talladas en madera o marfil, fueron utilizadas a modo de curiosidades para mostrar las diferencias físicas entre el cuerpo femenino y el masculino, así como empleadas como maniquíes durante las explicaciones que daban las parteras y los médicos a las pacientes para exponerles los detalles del diagnóstico. Además, estas muñecas anatómicas desmontables, que dejaban al descubierto sus órganos internos, formaron parte de espectáculos itinerantes propios de lugares poco científicos.
} 


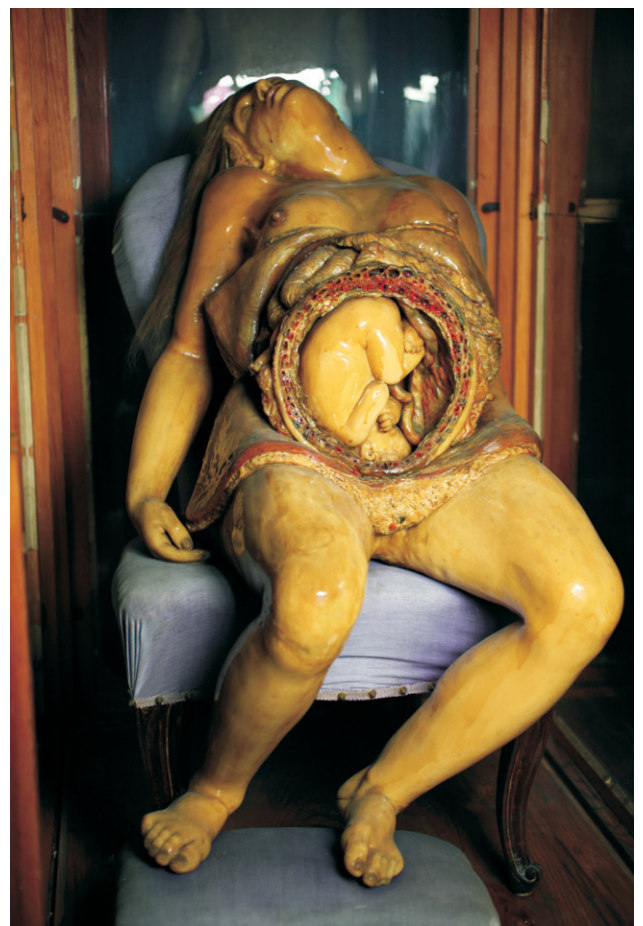

Fig. 10. Juan Cháez y Luigi Franceschi, $L a$ parturienta. Escultura de tamaño natural en cera, siglo XVIII. Museo Anatómico "Javier Puerta", n..$^{\circ}$ inv.: 138. Facultad de Medicina, Universidad Complutense de Madrid. La figura muestra un embarazo a término.

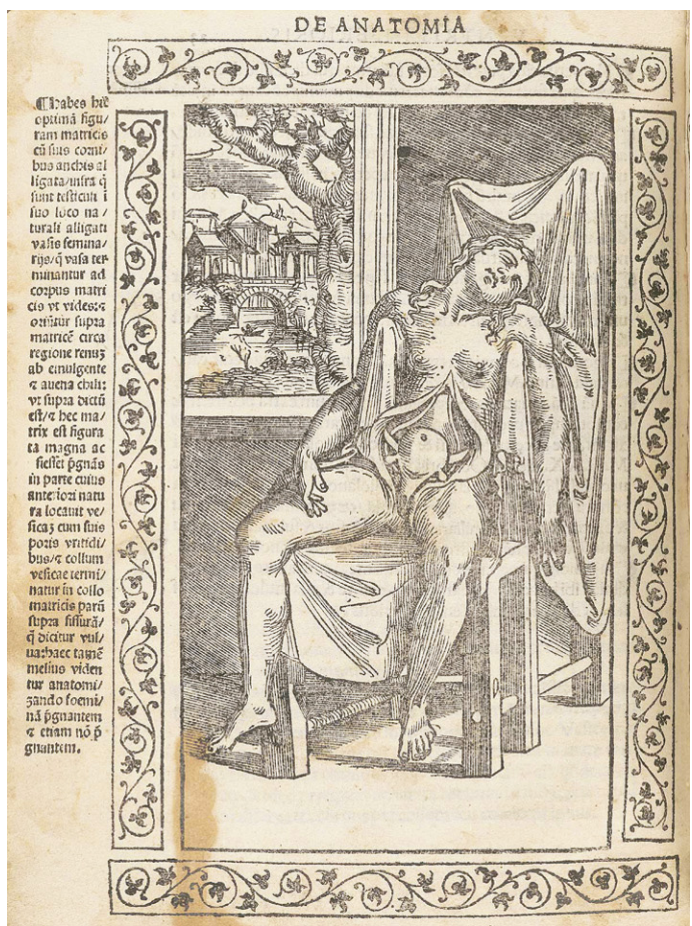

Fig. 11. Lámina 23v. Grabado que ilustra el tratado anatómico de Jacopo Berengario da Carpi, Isagogae breues, perlucide ac uberime in anatomiam humani corporis a communi medicorum academia usitatam, Bologna, Beneditcus Hector, 1523.

Antonio de Gimbernat y Mariano Rivas en relación con este asunto. El 30 de abril se les comunica que el rey ha accedido a su petición $p[o] r$ su notoria habilidad en este punto, pudiendo tambien servir p[a]ra moldar piezas del natural (...)".

Este artista, nacido en Málaga hacia 1750, pudo formarse en algún taller local trabajando a las órdenes de Fernando Ortiz o de Pedro Asensio, quienes gozaban de gran prestigio en el modelado de figuras en barro. Probablemente su traslado a Madrid se produjo como consecuencia del éxito alcanzado con su intervención en la decoración de los jardines de la finca de Santo Tomás de Churriana, lo que le posibilitó entrar en contacto con el círculo próximo al Real Infante Luis Antonio de Borbón, para el que realizó trabajos desde $1783^{50}$. Al verse en una situación económica complicada tras el fallecimiento del Infante, en 1785, Cháez buscó apoyo entre las relaciones influyentes e intentó que el monarca continuase pagándole el sueldo asignado por su hermano. En la misma época el artista solicitó trabajo "en la execución de alguna colección de obras, en la cual haya grupos, figuras sueltas, bajorrelieves, bustos y demás adornos que representen aquellos pasajes de historias capaces de servir de instrucción, así como todas las operaciones prácticas de las Artes y Ciencias que puedan demostrar el camino para conseguir sus

${ }^{50}$ El 9 de diciembre de 1783 comienza a recibir el sueldo anual de 12.000 reales por sus trabajos al servicio de este noble personaje. 
fines "51. Sus conocimientos técnicos, el dominio de los materiales y su extraordinaria habilidad para la elaboración de figurillas en barro cocido y cera, le llevaron a alcanzar un enorme reconocimiento en su faceta de escultor, siendo sus creaciones apreciadas por importantes personajes de la época, como Ponz ${ }^{52}$. El 14 de julio de 1790 dirige un Memorial al monarca en el que le expuso sus penurias económicas derivadas de las responsabilidades familiares. A los pocos días se le contrató para efectuar en el plazo de dieciocho meses una estatua de Venus, en mármol de Carrara y otras doce estatuas en barro, todas a tamaño del natural, para la casa de campo de la Alameda, pero Cháez incumplió el encargo y el 3 de mayo de 1792 tuvo que devolver 11.500 reales que había recibido a cuenta ${ }^{53}$.

Sus labores dentro del Gabinete anatómico se desarrollan en un período comprendido entre 1788-1806, otorgándosele 500 ducados anuales por ello que cobraría “(...) con la obligacion de trabajar baxo las órdenes de Dn. Antonio Gimbernat (...), debiendo presentar certificación “(...) $q(u)$ e acredite el desempeño de su obligacion (...)" ${ }^{54}$. Así, en abril de 1790 y con motivo de haber pedido Cháez la cantidad de 25 doblones para continuar la figura de cera en la que estaba trabajando, se solicitó un informe favorable al mismo. Los años fueron pasando y ya en 1806, el monarca determinó por Real Orden de 21 de mayo que Cháez fuese apartado de su destino "con el goze de 200 ducados anuales".

Usandizaga insiste en que la escultura de cuerpo entero, que él define como "Mujer a término yacente o Parturienta con el vientre abierto" es obra exclusiva del artista malagueño ${ }^{55}$; sin embargo, es curioso que, en un escrito posterior se contradiga y en el pie de foto de la susodicha pieza haga constar: "Ejecutada bajo la dirección de Lacaba por los escultores Juan de Chaez y Franceschi" ${ }^{56}$. Como constatan los documentos de archivo $^{57}$, este último ocupó el puesto de "artífice o constructor de piezas de cera" desde 1790, con un salario de 6.600 reales de vellón anuales, que cobraría de la Tesorería siempre y cuando presentase "certificacion mensual de Vm $q(u)$ e acredite haber cumplido exâctam(en)te su obligacion" bajo las órdenes e instrucciones del disector Lacaba, según se recoge en el manuscrito Copia de Reales Órdenes.

Poco sabemos de este artista que en los documentos aparece citado unas veces como Franceschi y otras como Luis Franchesqui. Natural del Ducado de La Toscana, concretamente de la ciudad de Volterra, se formó en el arte de la ceroplástica dentro de los talleres florentinos. Tal vez ejerció como ayudante jornalero en el taller de La Specola, durante el período comprendido entre 1781-1786, pues entre el listado de nombres que aparece recogido en el Libro de Registros se incluye el de Francisci, pudiendo tratarse de la misma persona. Allí debió de aprender el oficio de cero-escultor que posteriormente desarrollaría en Madrid trabajando conjuntamente con Juan Cháez $^{58}$. En el Libro de cuentas del Real Colegio quedan reflejados los diferentes pagos y las cantidades que se le dieron al artista italiano en concepto de la "construccion de piezas de cera" ${ }^{\prime \prime}$.

URREA, 2010: 136

52 Ponz, 1772-1794, T. XVIII (1794), carta V (ed. 1947, p.1646).

53 Archivo Histórico Nacional. Consejos-Osuna-Cartas. Legajo 393.

${ }_{54}$ Libro de representac(iones), respuestas y orden(anzas) de los años anteriores y R(eale)s Ordenes con arreglo a la ordenanza de (cirugía). Madrid, 1787-1817. BH. MSS 927.

55 Usandizaga, 1944: 235.

56 UsANDIZAGA, 1948: 69.

57 Gaceta Oficial del Colegio del viernes 12 de noviembre de 1790 (García del Real, 1934: 750-752)

58 GARCía del REAL, 1934: 156-157.

59 Libro de cuentas: entradas y salidas del caudal de dotación señalado al R(ea)l Colegio de San Carlos, establecido en Madrid: año de 1787 (-1815). BH MSS 926. Constan los recibos de 29 de abril, 8 de junio, 6 y 27 de julio, 14 y 19 de octubre de 1797, por una cantidad de 2016 reales de vellón; dos recibos de 24 de mayo de 1798, de 910 reales de vellón; un recibo de 15 de diciembre de 1798, de 400 reales de vellón; un recibo de 14 de marzo de 1799, de 9120

Arch. esp. arte, LXXXv, 340, octUBRE-DICIEMBRE 2012, 329-349, ISSN: 0004-0428 
A partir del año 1787 hay constancia de que Franceschi trabajó en la elaboración de piezas para la Universidad de Alcalá con permiso de Carlos $\mathrm{III}^{60}$, como indica el Libro de representaciones de 1787 a 1817 del Colegio, con fecha de 26 de febrero, en el que "S.M (...) se ha servido conceder al expresado Franceschi el correspondiente permiso paraq(u)e con las horas libres de su obligacion trabaje las piezas anatomicas q(u)e se le encarguen p(o)r el Regente y Cursantes de la Universidad de Alcalá y otros", señalando la obligación de que "[...] ninguna salga del Colegio sin haberla reconocido antes su Disector Dn. Ignacio Lacaba”. En la Academia de San Fernando se conservan varios documentos que abarcan el período comprendido de 1796 a 1803 , en los que se recoge la pretensión de este artista de ser nombrado Académico de mérito ${ }^{61}$. Alega como méritos ser autor de una estatua anatómica para la citada Universidad, de un grupo que representaba a Jesús entre los doctores en el Templo y de un bajorrelieve con la Degollación de los Inocentes.

En octubre de 1797 se encarga ${ }^{62}$ al citado modelador que, habiendo concluido la colección de partos, efectúe en cera las vísceras y un esqueleto mostrando los ligamentos (fig. 12). Para su representación posiblemente se utilizó como fuente de inspiración los grabados de las tablas IV y VIII contenidos en el Tratado Tabulae Sceleti et Musculorum Corporis Humani de Bernhard Siegfried Albinus $^{63}$ (fig. 13). En estos momentos la plaza de disector la ocupa D. Sebastián Aso, quién la obtuvo por oposición. Al haber dejado Lacaba su puesto - tras diez años de colaboración con Cháez y Franceschi-, los pagos comienzan, según el Libro de cuentas, a estar a nombre de Cháez, y, en otros casos, la mayoría de ellos, de Franceschi, por gastos de Gabinete en lo referente a la creación de modelos; por ejemplo “(...) para abonar las piezas de cera de los vasos linfaticos y demas" $" 64$.

En enero de 1801, fecha en que se vuelve a tener noticia en el Libro de acuerdos ${ }^{65}$ de los movimientos del Gabinete, se les sube el salario a Cháez y Franceschi, hasta 700 y 1.000 ducados respectivamente. El libro de cuentas marca, con pagos a Franceschi por piezas de cera, la continuidad de la labor creadora a lo largo de los años 1801-1806, sin interrupción, con mención en diciembre de 1803 de la elaboración de una pieza que muestra los vasos linfáticos. Por Real Orden, de 21 de mayo de $1806^{66}$, se separa a Cháez del Gabinete con un salario reducido a 200 ducados y se destina una suma de 500 ducados a la contratación de un joven escultor que supiese modelar con la denominación de Ayudante primero de constructor de piezas anatómicas, ocupando la plaza D. Dionisio (Giraldo) Berger ${ }^{67}$. A su vez, se contrata como Aprendiz o Ayudante segundo a D. Antonio Busquet. Ambos debían aprender la anatomía, tanto en teoría como

reales de vellón; un recibo de 30 de julio de 1801, de 100 reales de vellón; dos recibos de 7 de marzo y de 2 de mayo de 1801, de 8400 reales de vellón; tres recibos de 29 de enero, 23 de julio y 14 de diciembre de 1802 , de 1037 reales de vellón; recibos del 13 y 27 de abril, 20 de junio, 8 de noviembre y 19 de diciembre de 1803, de 1785 reales de vellón; recibos de 8 de febrero, 8 de junio y 11 de diciembre de 1804, de 924 ducados; recibo de 2 de octubre y 27 de diciembre de 1805 , de 802 ducados; recibos de 1 de octubre y diciembre de 1806, de 384.712 reales de vellón.

${ }^{60}$ Este monarca se caracterizó por un elevado interés hacia la presencia en la corte española de artistas italianos. Fueron éstos los que iniciaron el arte de la ceroplástica aplicada a la anatomía e influyeron con su técnica en la creación de los modelos artificiales de los gabinetes universitarios europeos (Vega, 2010a: 454).

${ }_{61}$ Archivo de la Academia. Arm.1, leg.42.

62 Acuerdos. Madrid, 1796-1800. (BH MSS 929) [Manuscrito].

63 B. S. Albinus (1697-1770) anatomista y profesor alemán. Dicha obra fue publicada por primera vez en Leiden, en 1749. Las ilustraciones contenidas en el libro fueron realizadas por el grabador Jan Wandelaar.

${ }^{64}$ Recibos de 30 de junio y 30 de diciembre de 1803.

${ }^{65}$ Libro de Acuerdos para el R[ea]l Colegio de Cirugía de S[a]n Carlos establecido en Madrid, año de 1787 [Manuscrito]. Madrid, 1787-1804 (BH MSS 930).

${ }^{66}$ Copia de [Reales] Órdenes, representaciones y respuestas: 1787 a 179[9]. Madrid, 1787-1806. (BH MSS 928) [Manuscrito].

${ }^{67}$ Real Orden de 9 de junio, comunicada el 16 del mismo año. 


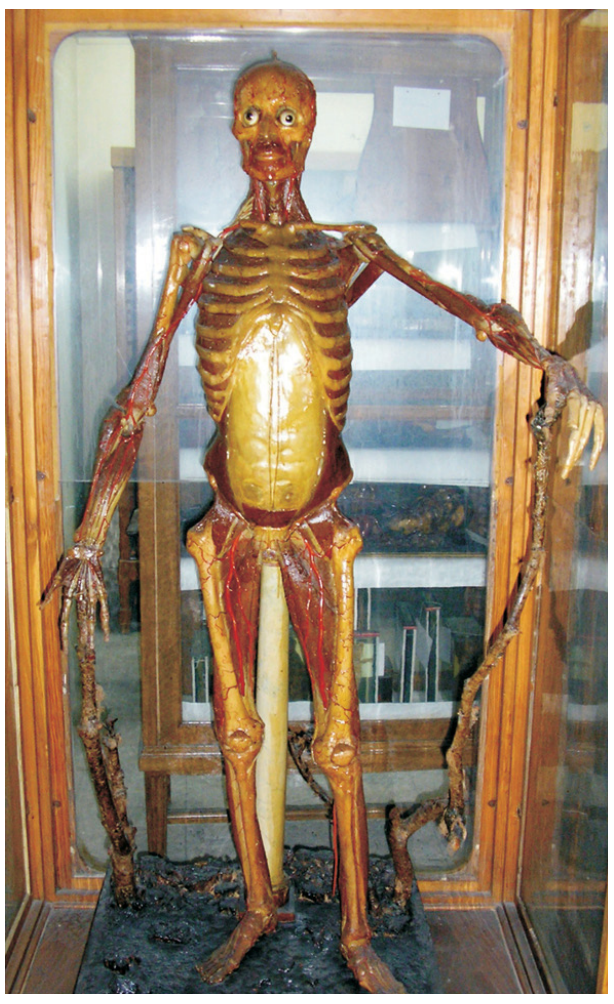

Fig. 12. Juan Cháez y Luigi Franceschi, Esqueleto con ligamentos, siglo XVIII.

Escultura de tamaño natural en cera,

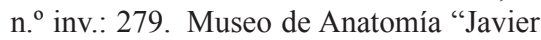
Puerta", Facultad de Medicina, Universidad Complutense de Madrid.

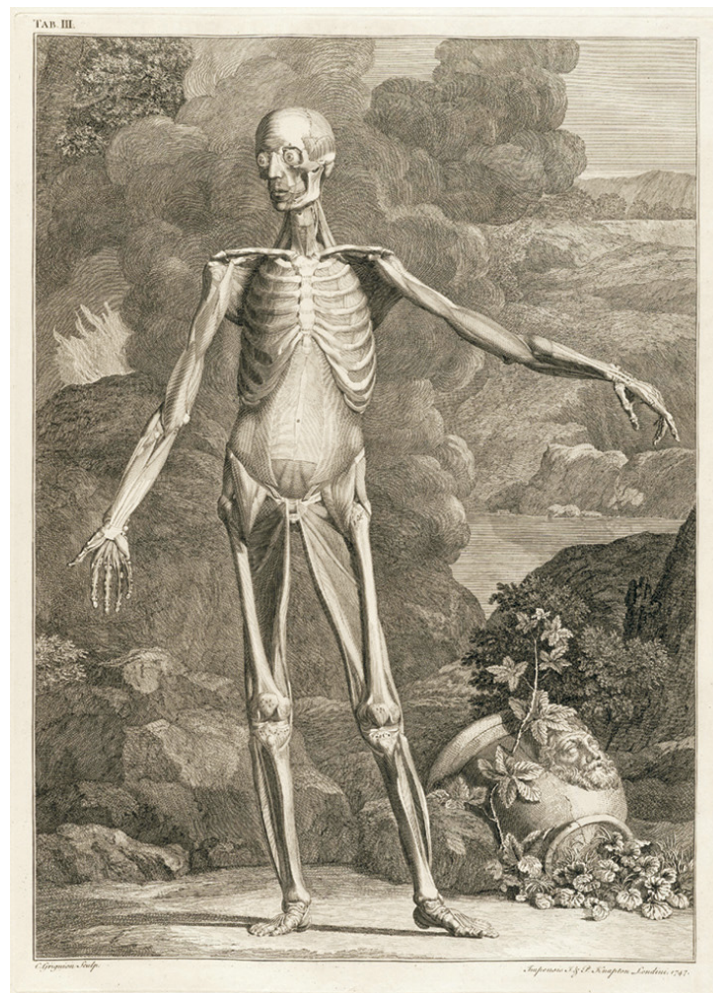

Fig. 13. Lámina Musculorum tabula III. Grabado de Jan Wandelaar. Ilustración contenida en el tratado anatómico de Bernhard Siegfried Albinus, Tabulae Sceleti et Musculorum Corporis Humani, Leyden: Johann \& Hermann, 1747.

en la práctica, y ser instruidos por Franceschi en el arte de hacer piezas de cera, dominando el dibujo y el modelado, con el fin de que pudieran "executarlas con la perfeccion correspondiente". En el mismo documento se señala la posibilidad de ascensos en función de sus logros: así, el ayudante primero pasaría a ocupar la plaza de Franceschi, cuando éste faltase, y el ayudante segundo la del primero.

Es muy probable que la muerte de Juan Cháez ocurriese un poco antes de la Guerra de la Independencia, pudiendo tener una edad aproximada de cincuenta y ocho años, a tenor de los datos que aparecen recogidos en la Gaceta del 2 de marzo de 1809, donde su nombre ya no aparece en el listado elaborado por orden del conde de Cabarrús, ministro de Hacienda. Sí constan dos hijos suyos, Francisco y Juan ${ }^{68}$, los cuales tributan una cantidad inferior a la del padre.

El 18 de febrero de 1806, D. Juan Bautista Guadrí, cirujano y profesor de anatomía en la Universidad de Bolonia, envía a través del Ministro del Rey de Milán una carta ofreciéndose a instalarse durante un tiempo en la corte madrileña con objeto de llevar a cabo piezas de cera al

${ }^{68}$ Se sabe que éste último inició sus estudios artísticos en 1798, pues su nombre aparece entre los matriculados ese año en las clases de la Academia de San Fernando. Archivo de la Academia. Libros de Matrícula. 
estilo de las que existían en Pavía y en Berlín. Sin embargo, se le deniega la petición ya que se considera que su trabajo no supondría ninguna ventaja pues ya había en el Colegio "sugetos muy capaces de emprender esta obra y llevarla á su fin (...) '"69.

El último apunte sobre los movimientos del Gabinete corresponde al 27 de diciembre de 1815 y se refiere a la ocupación de la plaza de segundo ayudante por Sebastián Aso de Marchena, cuyos trabajos se desarrollaron bajo la dirección del disector D. Ramón Trujillo, según ha quedado constancia en el Libro de representaciones.

Franceschi intentó en vano alcanzar los honores de Escultor de Cámara de Fernando VII. El 16 de septiembre de 1816, la Junta Gubernativa de Cirugía emitió un informe favorable ${ }^{70}$ en el que se reconocía el servicio de este artista durante veintiséis años a la Corte, destacando su habilidad para crear esculturas anatómicas en cera, pero el monarca pospuso el asunto.

A partir de este año, los manuscritos se ven interrumpidos y se continúan unas tras otras sus páginas en blanco, cerrándose el Colegio en el año 1928 coincidiendo con la unión definitiva de los estudios de Medicina y de Cirugía. La Corona finalmente crea la Universidad Nacional de Madrid, que abrió sus puertas en octubre de 1845. Se determina entonces que sería la Facultad de Medicina de Madrid la que proveería al resto de facultades de piezas artificiales, creando modelos que permitan la realización de copias de calidad.

\section{La compra de instrumental y materiales para la elaboración de los modelos}

La indiscutible capacidad técnica de los cero-escultores y anatomistas es valorada por la elección de los materiales más adecuados para obtener la perfección deseada en el artefacto en cera. Aunque los documentos de archivo no son muy explícitos en detalles sobre el procedimiento técnico, si ofrecen algunos datos de interés.

El primer pago que aparece registrado en el Libro de cuentas tiene fecha de 13 de septiembre de 1786 y se le hizo a Lacaba para cubrir los gastos ocasionados por la adquisición de modelos de yeso, moldes, colores, peanas y utensilios; asimismo, en esas fechas se debía de estar preparando una urna, referida como "caxon", destinada a albergar la figura femenina de cuerpo entero, pues aparece un pago de 30 de diciembre, de 8.182 reales de vellón, a un maestro cerrajero por el herraje de la caja, y otro de 8.342 por "la madera hechura y varas del mismo caxon" a un maestro carpintero ${ }^{71}$.

En 1787 la actividad del Gabinete continúa, se encargan utensilios y colores molidos al óleo para inyecciones por valor de 8.200 reales de vellón y consta un recibo de 23 de septiembre de 28.000 reales de vellón por seis piezas Anatómicas de cera más, encargadas a Lacaba, y otros tantos utensilios. Asimismo, hay encargo en el Libro de cuentas de piezas de cera y de mantenimiento del Anfiteatro, y compra de todo cuanto se necesite para el trabajo del Gabinete, con fecha de 8 de julio de 1788 , por la suma de 18.873 reales de vellón a Lacaba y se destina una partida de 200 reales para los enterradores.

Poco a poco el Gabinete iba aprovisionándose de todo el material necesario para las labores que se ejercían en sus dependencias y, así, a título de detalle, puede leerse en el Libro de Cuentas que, el 30 de agosto de 1788 se le pagaron al señor Josef García, la cantidad de 8.910 reales de vellón por una mesa para esculpir.

${ }^{69}$ Libro de representac [iones], respuestas y orden[anzas] de los años anteriores y R[eale]s Órdenes con arreglo a la ordenanza de [cirugía]. Madrid, 1787-1817 (BH MSS 927) [Manuscrito].

70 Archivo Palacio Real. Expedientes personales. Legajo F-38 antiguo; 8.838 moderno.

${ }^{71}$ Libro de cuentas: entradas y salidas del caudal de dotación señalado al R[ea]l Colegio de San Carlos, establecido en Madrid: año de 1787 [-1815] (BH MSS 926) [Manuscrito]. 
En 1789 este tipo de tareas continúan como puede deducirse, por la citación en el Libro de cuentas, del pago realizado al disector jefe, de 8.300 reales de vellón, por gastos de piezas de cera, con recibo de 9 de marzo. Una anotación posterior, del 23 de diciembre, habla de la adquisición por Cháez, de bermellón y yeso para el modelado de las figuras, por 8.090 reales de vellón, suma que resulta algo desajustada en relación a otros gastos, también menos definidos, del Gabinete. Los trabajos de ceroplástica siguen generando gastos durante 1792 y en los tres años siguientes que ascienden a 18.979, 18.449, 28.253 y 30.572 reales de vellón, respectivamente, según se anota en el Libro de cuentas.

Según se relata en la Copia de Reales Órdenes durante 1792 se solicita el diseño de una mesa que sirviera para depositar las preparaciones anatómicas y se requiere la presentación del mismo ante peritos para establecer si la cuantía requerida era la adecuada. En ese mismo año y manuscrito se recoge el acuerdo de "dividir con un tabique la sala de Diseccion desuerte q[ue] la ventana contigua al Gabinete quede comprendida en el nuevo quarto, el qual se extenderá hasta cerca de la Fuente, para que se puedan trabajar las piezas de cera, sin embarazar el Gabinete, sin estorvarse mutuam[e]te los q[ue] manipulan cera y los q[ue] disecan." A tenor de estas indicaciones se puede deducir que la sala de disección y el taller donde se elaboraban las ceras eran espacios contiguos.

El 18 de octubre de 1793 se decidió, según consta en la Copia de Reales Órdenes, que algunas de las láminas de Gauthier D'Agothy ${ }^{72}$, adquiridas en 1786, se colocarán en la sala de Juntas guarneciéndolas con marcos y cristales entrefinos.

Durante el año 1794 se destinan dos partidas a gastos derivados de la construcción de urnas para la figura de la "Parturienta" y la escultura de cuerpo entero de miología, como consta en los recibos de 31 de julio y 6 de noviembre, entregados a D. Francisco Amich.

A fin de otorgar realismo a algunas de las ceras obstétricas, se solicita al instrumentalista Tomas Maseras un fórceps por el que recibe la cuantía de 80 reales de vellón, con fecha 4 de marzo de 1795. En ese mismo año, según aparece en la Copia de Reales Órdenes, se aprueba la compra - propuesta por Lacaba-, de materiales para los trabajos de disección, gabinete y conservación de las piezas en él existentes, detallándose dos carros de carbón y aguardiente.

En el período comprendido entre 1795 y 1796 se observa un gran interés hacia la adecuada conservación de los modelos artificiales, pues se hace referencia a la imperiosa necesidad de poner unos cristales entrefinos y sin plomos a la vitrina de la escultura de miología en cera, que tras pocos meses de ser finalizada comenzaba a deteriorarse. Tras discutir sobre la conveniencia o no de los mismos, tales cristales son aprobados en febrero de 1797, pero serán normales y emplomados. Al mismo tiempo se propone una remodelación de la disposición del Gabinete, construyendo armarios específicos para las piezas en cera, con el fin de trasladarlas de su ubicación, en medio de la estancia, ya que entorpecían el trabajo diario.

Los gastos derivados de la compra de materiales y los destinados a pagar las labores de los cero-escultores continúan registrándose desde 1798 a 1806. La última anotación "por lo executado en el Gabinete de piezas anatomicas en cera" tiene fecha de octubre de 1806.

Sirvan estas líneas para contribuir al reconocimiento de la importancia y pertinencia del estudio en el ámbito de la historia del arte y de la medicina de esta tipología de esculturas al ser extraordinarios ejemplos que se sitúan, por un lado, en una particular posición como obras de arte que exaltan el ilusionismo y el realismo a modo de espectáculo visual, y por otro, como objetos científicos que permitieron la plasmación tridimensional de los avances alcanzados en el naturalismo anatómico.

\footnotetext{
72 Jacques Fabian Gautier d'Agoty (1717-1785), grabador francés discípulo de Le Blon. Utilizó mezzotinta en sus ilustraciones anatómicas. Sus dibujos se caracterizan por no tener el rigor científico de la precisión -ya que no carecía de estudios de medicina-, y estar guiados por la libertad creativa.
} 


\section{BIBLIOGRAFÍA}

Acuerdos. Madrid, 1796-1800. (BH MSS 929) [Manuscrito].

Archivo Histórico Nacional [AHN] (Madrid), Sección de Consejos Suprimidos, Legajo 5464. Expediente 14, Representación de Francisco Antonio de Zunzunegui, 1783.

Álvarez Sierra, José, "Historia de la Escuela de Medicina de Madrid. Colegio de San Carlos", en Ciencias Médicas Hispano-Americanas, Tomo 8 (Fascículo 44), 1955, pp. 251-263.

Aparicio Simón, José, Historia del Real Colegio de San Carlos de Madrid, Madrid, Publicaciones de la Universidad de Madrid, Tesis Doctorales, Aguilar, 1956.

Ballestriero, Roberta, "Anatomical models and wax Venuses", en Journal of Anatomy (2010) 216, pp. 223234.

Bonélls, Jaime; Lacaba, Ignacio, Curso completo de Anatomía del cuerpo humano. Madrid, Imprenta Sancha, 1796.

Burke, Michael E., The Royal College of San Carlos. Surgery and Spanish Medical Reform in the Late Eighteenth Century, Durham, Duke University Press, 1977.

Copia de [Reales] Órdenes, representaciones y respuestas: 1787 a 179[9]. [Manuscrito]. Madrid, 17871806. (BH MSS 928) [Manuscrito].

Costa Carballo, Carlos Manuel, La enseñanza de la medicina a finales del siglo XVIII en las instituciones docentes madrileñas ubicadas en el Hospital General de Madrid, Tesis Doctoral, Universidad Complutense de Madrid. Facultad de Medicina. Departamento de Medicina Preventiva, Salud Pública e Historia de la Ciencia, Madrid, 1991.

Costa Carballo, Carlos Manuel, "Otros materiales utilizados para la enseñanza de la medicina en el Real Colegio de Cirugía de San Carlos de Madrid (1788-1826)", en Asclepio, LV (1), 2003, pp. 35-137.

Estella Marcos, Margarita, "Obras maestras del Arte de la cera en España”, en Goya, n. ${ }^{\circ}$ 237, (1993), pp. 149160.

Estella Marcos, Margarita, "Pequeña escultura en cera: nuevas noticias sobre obras de Francisco Pieri y Caterina de Julianis en España", en Boletín de la Real Academia de Bellas Artes de la Purísima Concepción, 44, (2009), pp. 75-84.

García del Real, Eduardo, Los anatómicos y los cirujanos del siglo XVIII, el Dr. Antonio Gimbernat y la Fundación del Colegio de San Carlos / conferencia de E. G. ${ }^{a}$ del Real, Madrid, Academia Nacional de Medicina, 1934.

García Guerra, Delfín, La Facultad de Medicina de Santiago en el siglo XIX, Universidad de Santiago de Compostela, 2001.

Gimbernat, Agustín, Sucinta noticia del S.D. Antonio de Gimbernat, Barcelona, Imprenta de Sierra y Martí, 1828.

González Palacios, Alvar, "Retablillos en cera", en FMR, n. ${ }^{\circ}$ 20, (1993), pp. 41-66.

Libro de Acuerdos para el R[ea]l Colegio de Cirugía de S[a]n Carlos establecido en Madrid, año de 1787 [Manuscrito]. Madrid, 1787-1804 (BH MSS 930).

Libro de cuentas: entradas y salidas del caudal de dotación señalado al R[ea]l Colegio de San Carlos, establecido en Madrid: año de 1787 [-1815] (BH MSS 926) [Manuscrito].

Libro de representac[iones], respuestas y orden[anzas] de los años anteriores y R[eale]s Órdenes con arreglo a la ordenanza de [cirugía]. Madrid, 1787-1817 (BH MSS 927) [Manuscrito].

Massey, Lyle, "Pregnancy and Pathology: Picturing Childbirth in Eighteenth-Century Obstetric Atlases", en The Art Bulletin, vol.87, n. 1 (Mar., 2005), pp. 73-91.

McTavish, Lianne, Childbirth and the Display of Autority in Early Modern France, Adelshort, Ashgate, 2004.

Morris-Kay, G.M., "The evolution of human artistic creativity”, en Journal of Anatomy, (2010), 216, pp. 158176.

Pardo Canalis, Enrique, "Noticias del escultor Juan Chaez", en Archivo Español de Arte, 28:109, (1955: enero/marzo), pp. 73-84.

Pardo Canalis, Enrique, "Escultores italianos de los siglo XVIII y XIX en España", en Archivo Español de Arte, 28: 110, (1955 abr/jun.), pp. 97-115. 
Park, Katharine, Secrets of Women. Gender, Generation, and the Origins of Human Disection. New York, Zone Books, 2006.

Real Cédula de S.M. y señores del Consejo por la qual se manda establecer en Madrid un Colegio y Escuela de Cirugía... En Madrid: en la imprenta de D. Pedro Marín, 1780.

Riera, Juan, Anatomía y Cirugía Española del siglo XVIII (notas y estudios), Valladolid, Secretariado de Publicaciones, 1982.

Salcedo, Enrique, Obras de Antonio de Gimbernat precedidas de un estudio Bio-bibliográfico del mismo, Madrid, Biblioteca clásica de la Medicina Española, 1927 (2 tomos).

Urrea, Jesús, “Apuntes para el estudio de la escultura en cera en España”, en Boletín del Seminario de Estudios de Arte y Arqueología, tomo 45 (1979), pp. 488-495.

Urrea, Jesús, "Una propuesta para el escultor Juan Cháez", en Ars Magazine, n. o 6 (abril/junio 2010), pp. 94103.

Urrea, Jesús, "La corrida de toros vista por el escultor Juan Cháez", en Taurus. Del mito al ritual, Museo de Bellas Artes de Bilbao, 7 de junio-5 de septiembre de 2010, pp. 131-139.

Usandizaga, Manuel, Historia de la obstetricia y de la ginecología en España, Santander, 1944.

Usandizaga, Manuel, Historia del Real Colegio de Cirugía de San Carlos de Madrid (1787-1828), Madrid, Consejo Superior de Investigaciones Científicas, MCMXLVIII.

Vega, Jesusa, Ciencia, arte e ilusión en la España Ilustrada, Madrid, Polifemo, 2010(a).

Vega, Jesusa, "Otros espacios de sociabilidad ilustrada: el gabinete de cera", en Hispanic Research Journal. Iberian and Latin American Studies, vol. 11, n. ${ }^{\circ}$ 5, (2010), pp. 434-450 (b).

Fecha de recepción: 25-XI-2011

Fecha de aceptación: 10-I-2012

Arch. esp. arte, LXXXV, 340, OCTUBRE-DICIEMBRE 2012, 329-349, ISSN: 0004-0428 